\title{
O PATINHO FEIO NO IMAGINÁRIO PARENTAL
}

Laura Kolberg Lipp, Ana Beatriz Guerra Mello

e Marianne M. Stolzmann Mendes Ribeiro

Laura Kolberg Lipp

Acadêmica formanda

de Psicologia do

Centro Universitário

Feevale (2009/01)

e estagiária do

Centro Integrado

de Psicologia da

Feevale.

Ana Beatriz Guerra Mello

Psicóloga, mestre

em Educação pela

UFRGS, professora

de graduação e

supervisora no

Centro Integrado

de Psicologia do

Centro Universitário

Feevale. Psicóloga

Clínica do

Departamento de

Saúde da Mulher de

São Leopoldo-RS.

Marianne M. Stolzmann

Mendes Ribeiro

Psicóloga, mestre

em Psicologia

Clínica/PUCRS,

professora do Centro

Universitário Feevale

e supervisora do CIP

(Centro Integrado

de Psicologia). É

psicóloga do Ciaps

(Centro Integrado

de Atenção

Psicossocial),

Hospital

Psiquiátrico São

Pedro. Psicanalista,

analista membro da

Appoa (Associação

Psicanalítica de Porto

Alegre).
RESUMO: O presente artigo propõe-se a discutir o tema da adoção, partindo de um caso clínico atendido através da Psicoterapia Breve Dinâmica no Centro Integrado de Psicologia — Feevale. Frente ao caso trabalhado, objetiva-se compreender o lugar que a criança adotada é convocada a ocupar no contexto familiar. O estudo aponta para diversas respostas à questão, que dizem respeito à adoção enquanto construção de um imaginário parental e as possíveis implicações no sujeito adotado quando a mesma não é revelada.

Palavras-chave: Adoção, segredo, imaginário, psicanálise, psicoterapia breve.

ABSTRACT: The Ugly Duckling and parental imaginary. This article proposes to discuss the issue of adoption based on a clinical case observed in a Brief Dynamic Psychotherapy at Centro Integrado de Psicologia - Feevale. In this case, the authors aimed to understand the place that the adopted child is requested to occupy in the family. The study highlights several possible answers to the question, concerning adoption as a construction of a parental imaginary and the possible implications for the child when the adoption is not revealed.

Keywords: Adoption, secret, imaginary, psychoanalysis, brief psychotherapy. 


\section{INTRODUÇÃO}

Tendo em vista a proposta de discutir a temática da adoção, o presente artigo parte de uma vivência clínica realizada no Centro Integrado de Psicologia da Feevale (CIP), em Novo Hamburgo/RS. O CIP caracteriza-se por se tratar de uma clínica-escola, estruturada como um projeto extensionista da instituição. No que se refere ao atendimento clínico, a supervisão sustenta sua prática pela compreensão psicanalítica e intervenção breve dinâmica. Conforme Enéas, Faleiros e Sá (2000), a psicoterapia breve é entendida como uma escolha favorável ao se tratar de uma clínica-escola, uma vez que atende mais apropriadamente a comunidade almejada. Proporcionando maior número de pessoas beneficiadas, menor fila de espera e tratamento contínuo, com início, meio e fim, sem haver necessidade de trocas de terapeutas.

A psicoterapia breve se destaca pelo seu número delimitado de sessões, as quais são trabalhadas a partir de um foco, muitas vezes associado à queixa circunscrita trazida pelo paciente. Ao paciente, faz-se necessário a motivação e capacidade de produzir mudanças. O foco, no tratamento breve, é a peça-chave para esta modalidade, pois além de este limitar as intervenções, possibilitando o número restrito de sessões, é também a partir dele que se pode encaminhar uma alta. Isto porque, à medida que há uma questão específica a ser trabalhada, abre-se a possibilidade de avaliar se esta foi ou não de fato atingida (CORDIOLI, 1998).

No que se refere ao tema da adoção, entendemos que no ser humano é comum o desejo pela maternidade e paternidade. Para a psicanálise, existe a compreensão de que o filho vem, inconscientemente, dar seguimento ao nome dos pais, bem como corresponder às expectativas parentais de realizarem aquilo que não foi possível a eles, tanto no plano biológico quanto psíquico (LEVINZON, 2004).

A adoção é um tema bastante complexo conforme apontam alguns autores (SANCHES, 2002; LEVINZON, 2004). Para Levinzon, a ação de adotar proporciona à criança uma família, um lar onde receberá carinho e cuidados para crescer sadiamente, incluída numa base social segura. Aos pais, a adoção oportuniza que realizem o desejo de ter um filho.

Quanto à compreensão acerca da adoção, Dolto (1996/2004), traz algumas contribuições neste sentido. Trabalha, por exemplo, com a ideia de que não há uma idade específica para a revelação de uma adoção, aliás, ressalta que esta jamais deve ser escondida. Assim como a gravidez, a adoção deve ser compartilhada, mesmo quando a criança ainda não entende bem o significado da palavra. Da mesma forma, a adoção deve ser anunciada, contada à criança e às pessoas que fazem parte do círculo de relações destes pais, pois na medida que a criança cresce ouvindo seus pais verbalizarem a respeito dela, aos poucos passa a entender o que esta palavra significa. Ao contar a amigos e parentes, Dolto salienta que a adoção deve ser anunciada pelos pais como algo natural e verdadeiro. A todo 
sujeito é necessário o conhecimento de sua história; a respeito disso, Sanches (2002) desenvolve uma metáfora: "assim como as raízes de uma árvore sustentam sua estrutura, é essa história que possibilita a criança sentir-se como um ser que pertence a algo maior e que vai dar sentido às experiências que tem" (p.73). Conforme Mannoni (1987), na medida em que se delega inconscientemente um segredo a uma criança, como o de não contar sua história, a adoção, produz nela, muitas vezes, um sintoma. Sintoma esse, estruturado como linguagem cifrada, do qual se encarrega de conservar o segredo.

Da mesma forma, Sanches (2002) ressalta que a dificuldade em relação à verdade, no que diz respeito à adoção é, primordialmente, uma questão dos adultos, que uma vez atravessados pelo discurso social, defendem a ideia de que a criança já sofreu o suficiente com o abandono da mãe biológica, permitindo aos pais omitir a adoção e silenciar-se frente a esta difícil história, como se assim pudessem poupá-la do sofrimento. É como se a omissão fosse a melhor escolha, quando bem se sabe que são questões como essas que inserem as crianças em um lugar de não saber, isto é, no lugar de sintoma parental. Conforme Fernandez (1991), não existe segredo circunscrito a uma única pessoa, visto que esse age tanto naquele que o comunica, como naquele que o recebe.

Para Dolto (1996/2004), a palavra adotado quer dizer o mesmo que escolhido, entendendo-se escolhido como aquele que opera o lugar de filiação. Conforme Menegotto (2006), a filiação, por assim dizer, resulta de uma inscrição simbólica na criança, a qual visa o lugar de reconhecimento e pertencimento desta no contexto familiar e social do qual faz parte. Hoyer (2006), frente a esta concepção, acrescenta que cabe ao Outro, enquanto função constituinte, nomear e incluir o sujeito na rede de filiação simbólica, tomando-o como seu filho. Tal movimento inscreverá a criança no processo de filiação; diante disso, pode-se dizer que toda criança, para ser reconhecida como filha, deve ser adotada por seus pais, sendo eles biológicos ou adotivos (MENEGOTTO, 2006; LEVINZON, 2004). Conforme Bernardino (1999), um dos fatores que autorizam uma adoção é a prova de um desejo pelo filho. No caso que será apresentado a seguir, questiona-se o que sustenta o desejo pela adoção e como se dá o lugar de filiação.

Julien (2000) afirma que todo o bebê, pouco após o nascimento, evidencia a angústia em relação ao desejo do Outro Materno representada pela interrogação: "O que quer ela de mim?". Da mesma forma, esta interrogação se inscreve na criança adotada quando seus pais adotivos a levam para casa. Contudo, antes mesmo do nascimento, ou de uma adoção, a criança já é imaginada, falada e sonhada como resultado do desejo inconsciente do Outro Primordial, encarnado pela mãe (HOYER, 2006). Frente a esta colocação, abre-se outro questionamento: que lugar a criança adotada é convocada a ocupar no imaginário parental? 


\section{TECENDO O CASO: O LIVRO CADEADO}

O presente trabalho discutirá o caso clínico de Denis (nome fictício), um menino de sete anos que vem trazido pela mãe com queixa de dificuldade escolar. Além disto, segundo ela, em casa e na escola era muito agressivo, queria ser sempre o primeiro e que tudo fosse feito à sua maneira. Apresentava dificuldade para acatar limites e regras, o que não era apenas uma observação dos pais, mas também se evidenciava nos atendimentos, pois, durante as brincadeiras, demonstrava dificuldade em jogar conforme as regras. Assim, combinações eram estipuladas no caso das regras serem burladas. Frente a tais combinações, Denis oferecia resistência para cumpri-las. Em determinada sessão, tendo que se haver com o acerto de uma combinação, larga as peças do jogo sobre a mesa e sai da sala de atendimento descontente. Também por meio dos seus desenhos isto pode ser observado, pois Denis demonstrava dificuldade em colorir limitando-se à margem das folhas e contorno das figuras. Quanto aos problemas de aprendizagem, percebeu-se ainda a dificuldade de simbolização das letras do alfabeto, baseando seu aprendizado pela via da repetição. Sua fala era infantilizada, parecendo a de um bebê. A mãe relata que o menino possuía boa capacidade de memorização, mas não prestava atenção nas informações que recebia: segundo ela, Denis "vive no mundo da fantasia, adora estórias, contos de fadas...” (sic).

Denis foi adotado com cerca de um ano e meio de idade. Sua mãe biológica perdeu a guarda por negligência e, em consequência disso, foi abrigado. Contudo, também no abrigo, segundo relato dos pais adotivos, não era bem cuidado. Depois de concretizada a adoção, Denis ganhou uma família que o recebeu com carinho, de braços abertos. Os anos se passaram e sua adoção não havia sido revelada, sendo mantida como um segredo por seus pais. No que se refere a esta problemática, diversos autores ressaltam a importância da verdade e da palavra frente à história de uma criança. No que se trata da adoção, o princípio é o mesmo, apesar do que circula no senso comum de que a adoção deve ser tratada como algo velado, não anunciado. Contudo, uma vez não falada sua história, recai sobre a criança o escoamento do conflito entre o seu saber inconsciente e o seu não saber consciente. A exemplo disso, podem ser evidenciadas falhas fundamentais frente à estruturação psíquica e construção de identidade; além disto, diante de segredos como este, a criança é convocada a submeter-se enquanto sintoma na economia psíquica dos pais, sendo muitas vezes aí alimentado pelo gozo parental (MANNONI, 1987; MOLINA, 2001; LEVINZON 2004; SANCHES, 2002). Frente a estas questões, Mannoni (1987) acrescenta: “O que conta não é o acontecimento real, mas a mentira do adulto em torno do incidente. A criança se vê, então, diante de um dilema: denunciar a mentira, o que a salvaria, ou se mistificar" (p.45), entendendo mistificar no 
sentido de que há um lugar favorável à criança para que não denuncie a mentira, pois, assim como o sintoma, ela está ali por necessidade familiar.

A queixa de dificuldade escolar vem para denunciar o "não saber" sobre a adoção. Sendo assim, entendemos o foco terapêutico como sendo a anunciação da adoção e, por consequência, o acesso ao saber como forma de diminuição dos sintomas. Diante disso, trabalhou-se a verdade enquanto abertura para o saber, visto que colocar suas experiências em palavras possibilitou à criança dar sentido a esse lugar que foi convocada a ocupar, seja tomando-o para si ou protestando-o. Da mesma forma, para a psicanálise, à medida que a criança passa a conhecer sua história, seu mundo, é permitido a ela desvendar o mundo que a cerca, possibilitando apropriar-se da cultura na qual está inserida. Pois, o que resta afinal a uma criança que não tem o alcance ao saber? Resta não saber, não aprender, isto é, resta-lhe a ignorância (MANNONI, 1987; SANCHES, 2002).

A função da ignorância, para Paín (1991), estaria entre o conhecimento e o desejo; nesse sentido, a ignorância não obedece à estrutura de pensamento, mas sugere uma separação tênue entre o desconhecimento do pensamento lógico ao significante, o que permite "a ilusão de ser, de escolher, de apropriar-se, de ter um destino, de suportar sua insignificância” (p.12). Por razões como essas, o silêncio, a omissão e a falta de verdade é que tornam comum a procura por atendimento infantil, devido a queixas relacionadas à dificuldade escolar e problemas de aprendizagem. Ainda quanto à dificuldade de aprendizagem, Fernandez (1991) acrescenta, quando o problema é de ordem de um "sintoma” ou “inibição”, há consequências na articulação entre os níveis do desejo, organismo e corpo, levando a um aprisionamento da inteligência e do corpo em razão da estruturação simbólica inconsciente. Logo, é necessário verificar a história de vida do paciente e a necessidade de seu sintoma no sistema familiar.

Conforme Sanches (2002), em casos como esses, “pensar significa poder descobrir o 'inominável', sendo então, melhor não pensar. Vê-se, por aí, que as dificuldades escolares destas crianças, na realidade, são produto de um ato inteligente: proteger-se do perigo de saber que vai gerar dor” (p.74). É possível que diante de circunstâncias como esta a criança se sinta enganada, podendo inclusive ter sua confiança abalada frente a estes pais. Ela passa a ficar confusa diante de sinais que vinha captando de forma inconsciente, mas cujo saber é fragmentado. É como jogar quebra-cabeça, jogo favorito de Denis, com peças faltantes, em que no lugar de um significado criam-se buracos, espaços vazios. A respeito disso, Lacan (1964/1998) tem a acrescentar: “O inconsciente, primeiro, se manifesta para nós como algo que fica em espera na área, eu diria algo de não-nascido. Que o recalque derrame ali alguma coisa” (p.28).

Compreendendo a função da verdade, buscou-se trabalhar juntamente com os pais, estimulando-os a revelar a história de Denis, bem como comunicar-lhe 
o fato de sua adoção. Importante ressaltar que a criança não tem conhecimento consciente de que foi adotada; no entanto, este saber já existia, visto que ainda antes de nascer e, no caso deste menino, por mais um ano e meio de sua vida, algo desta experiência anterior já estava inscrita no seu inconsciente (SANCHES, 2002).

Diante dessa problemática e da importância do estudo psicanalítico nos primeiros meses de vida de um bebê, considerando o estágio do espelho e as marcas impressas da relação mãe-bebê, entendemos ser necessário discutir essas questões a partir do caso de Denis. Conforme Spitz (1979/1996), no primeiro ano de vida, todo bebê apresenta momentos de prazer e desprazer. Para o autor, o bebê, na relação com sua mãe, experimenta desprazeres, principalmente pela falta do olhar materno, por exemplo, quando uma mãe não sabe reconhecer em seu filho se ele tem fome. No que se refere ao manejo do bebê, Bernardino (2007) acrescenta que a ele é preciso primeiramente “'ser’ um corpo para ter um 'corpo' sendo requisito para tal que um Outro cuide e nele faça inscrições dessa outra ordem que é a linguageira” (p.54).

Mas o que se produz na criança quando esse rosto materno a abandona? Neste sentido, faz-se importante considerar, no caso de Denis, o discurso inconsciente dos pais, que aponta para a hipótese de que há, na relação entre o menino Denis e sua mãe adotiva, um conflito procedente de sua relação com a mãe biológica. Segundo relato dos pais adotivos, sua mãe biológica deu à luz a 12 filhos além de Denis, tendo assim bastante dificuldade em oferecer a ele os devidos cuidados. Em consequência, muitas vezes delegava a outros a tarefa da atenção materna a Denis, e desde então o vinha abandonando. No abrigo, o menino chegou bastante sujo e com vermes, denunciando os maus cuidados e o olhar materno essencialmente ausente e desprazeroso. Para Bernardino (2007), “Este Outro ao lhe propor um lugar, imprimirá imagem e significantes fundadores, a partir desse mais além que são os registros do Imaginário do Simbólico.” (p.55). Ao avaliar seus primeiros meses de vida, abre-se a pergunta: que representação psíquica tem Denis de uma mãe?

Frente a esta questão, destaca-se a fala de sua mãe adotiva: "ele tem boa capacidade de memória, mas é desatento” (sic). Neste caso, o que quer dizer sua mãe adotiva quando fala da sua capacidade de memorização? Seria algo referente ao que ele lembra? Ele lembra de sua mãe biológica? Como é sua lembrança? Recorda de ter sido mal cuidado, de ter ficado sujo? Diante destas questões, supõe-se um desejo de conforto dessa mãe adotiva, como se ela pensasse que apesar da boa memória do filho, ele é desatento, distraído, podendo, então, não recordar que ele teve uma mãe antes dela, e ainda de ter sido mal cuidado. Mesmo assim, parece permanecer com esta mãe a dúvida: afinal, mãe é uma só? Ou: quem é a mãe verdadeira? Para este menino, lança-se a hipótese de um recalque acerca 
do rosto materno biológico, o qual lhe proporcionou desprazeres significativos, conforme dados da anamnese. O recalque, enquanto "processo de afastamento das pulsões, às quais é rejeitado o acesso à consciência” (CHEMAMA, 1995, p.185), vem a favor de dar conta da dor vivenciada.

Apesar de os pais de Denis terem se mostrado, num primeiro momento, resistentes em realizar a revelação da origem do menino, postergando a anunciação da mesma e, de certa forma, mostrando-se desorientados sobre a melhor maneira de fazê-lo. Na medida que tais resistências eram trabalhadas em sessão, foram então se diluindo. Isto possibilitou a eles revelarem a adoção a Denis, o que foi realizado em casa enquanto olhavam o álbum de fotos. Em paralelo a esse processo, as sessões com Denis prosseguiam, e, em determinado atendimento, num momento posterior à anunciação da adoção, trabalhou-se o desenho da família. Isto possibilitou que Denis pudesse ilustrar sua compreensão psíquica acerca de sua história e seu lugar no contexto familiar.

Diante de tal solicitação, Denis desenha, de canetinha preta, um livro, um livro preto carregado de inúmeros cadeados, e, na ponta esquerda, uma chave, que, segundo ele, era para fechá-lo. De um lado da folha desenha o pai, um pai caracterizado de mãe com enormes braços e com o sinal gráfico til (“ ”), característico da palavra mãe, sob a letra "a” da palavra pai. A mãe, por outro lado, é desenhada sem braços no outro extremo da página. Supomos ser essa uma expressão do recalque de sua mãe biológica. No centro da folha, entre as duas figuras, esboça uma criança, mas sem terminá-la, risca por cima. No verso da folha, desenha a si mesmo e suas duas irmãs. Por fim, ao lado, desenha uma casa, a sua casa, trazendo o colorido num espelhamento à terapeuta que desenhava com diversas cores ao seu lado. Para Aberastury (1996),

“A criança expressa em suas brincadeiras as fantasias inconscientes recalcadas, e é por isto que, mediante a análise da atividade lúdica, temos acesso às experiências mais profundamente recalcadas da criança, estando em condições de exercer uma influência radical sobre seu desenvolvimento." (p.20)

Durante as sessões, ficou claro que a função materna é realizada primordialmente pelo pai, o que Denis assinala em seu desenho, sendo ele quem faz o holding. A mãe aparece, no discurso parental, como figura mais autoritária, sendo a pessoa que impõe as regras e limites, ocupando assim o lugar da função paterna. Tal assinalamento pode ser entendido no sentido de que houve um abandono do lugar materno pela mãe biológica, compreendendo que, para esta família, talvez tenha sido necessário se reordenar quanto à ocupação das funções paterna e materna. Para que a função materna pudesse ser operada, talvez tenha sido necessário o rosto do pai, um rosto novo para uma nova relação. Já para que 
essa mãe pudesse entrar numa relação com o menino, talvez tenha sido preciso que ela lhe oferecesse um lugar na função paterna. Quanto às funções materna e paterna, sabe-se que, para a psicanálise, o seu exercício não depende do gênero, mas sim do lugar que é ocupado na relação com a criança (OUTEIRAL, 2005).

No desenho, Denis cerca de cadeados seu livro, mas a serviço de que eles estão presentes na sua história? Os cadeados são parte da elaboração do conteúdo revelado na sessão anterior, mas também nos fazem pensar que podem estar ligados ao que ainda permanece oculto. Muitos autores colocam que em casos nos quais há saberes ocultos, não revelados, a criança então não se apropria da história contada, o que pode repercutir numa falha significativa na construção da sua subjetividade (MANNONI, 1987; MOLINA, 2001; SANCHES, 2002). No dia em que a mãe de Denis traz a notícia de ter anunciado a adoção, ilustra bem este fato quando o menino acrescenta ao discurso materno: "a história que minha mãe inventou” (sic). Mas o que quer Denis dizer com história inventada? Seria uma negação? Haveria a necessidade de mais tempo para ser internalizada? Ou seria mais uma história inventada? Ou ainda, será que haveria mais dessa história a ser contada? Considerando tal anunciação de uma história inventada, e os questionamentos feitos acima, entendemos ser importante retomar a história de Denis. Para tanto, os pais foram solicitados novamente a contar sua história e anunciar sua adoção, mas agora em sessão.

Amarradas à história de Denis, há as histórias dos demais filhos do casal. Eles tiveram duas filhas biológicas, uma mais velha e outra mais nova do que ele. A mais nova nasceu cerca de oito meses após a efetivação da adoção de Denis. Com esta ele rivaliza muito, ao mesmo tempo que, em alguns momentos, parece querer ser a irmã, como na primeira sessão em que lhe pedi que escrevesse seu nome e, na folha, surge o nome dela. É possível que tal rivalidade se dê em razão de que Denis vê na sua irmã a relação desta com a mãe, dual, de simbiose, qual ele não teve acesso com a mãe adotiva, procedendo, então, o seu desejo de ocupar este lugar da irmã na relação com a mãe. Diante do discurso parental, principalmente materno, subentende-se que essa é a filha admirável, enquanto Denis é descrito como o filho fracassado. Segundo a mãe, há momentos em que ela sente muita raiva do filho, principalmente quando ele recusa ordens, fica que "nem pode vê-lo" (sic).

Sabe-se que tanto o olhar parental como o discurso a respeito do filho são constituintes para este pequeno sujeito. Bastos (1999) salienta que mesmo antes do nascimento de um filho, um olhar e uma voz desenvolvem expectativas e vislumbram um lugar para esse. A partir do que se fala a seu respeito, que olhares se lançam a essa criança, tudo isso possibilita à mesma desenvolver sua própria imagem; para o autor, seria o mesmo que dizer que a criança nasce a partir da 
fala, do discurso parental. Mas qual seria a imagem que Denis construiu para si? Qual a imagem parental de Denis? O que falam seus pais?

No caso de Denis, os pais utilizam o discurso de fracasso acerca do filho, fala esta calcada no discurso social acerca da adoção, diluído no Outro e que toma a palavra dos pais. Os pais associam as características comportamentais que reprovam no filho àquelas que seriam originárias de sua mãe biológica. A exemplo disso, houve uma vez em que a mãe adotiva, ao se referir à mãe biológica, disse: "porque a mãe dele, sabe, ela é 'da vida', ela fuma, e eu já vi ele pegando cigarro do chão... isso só pode vir dela” (sic). Diante dessa fala, fica claro que em momentos como este a mãe adotiva se destitui do lugar materno, apresentando falhas nesta relação, que dizem respeito ao processo de filiação. Quanto a esta questão, Bernardino (1999) refere que há, na relação de pais e filho, adotantes e adotado, uma contradição, em que, por um lado, a criança é identificada como filho e, por outro, não corresponde ao lugar idealizado de filiação; como exemplo disto, a autora traz a seguinte frase: "isto se explica pelo fato de seu sangue ruim” (p.77). Discursos como esses são comuns na adoção, como outro exemplo, Sanches (2002) acrescenta: "Ele não nega os genes, é assim porque não veio de mim” (p.75). Para tanto, Julien (2000) assinala: “O social, que invade o domínio do político, avança de agora em diante sobre o território familiar. De fato cada vez mais representantes da sociedade intervêm na relação entre pais e filhos" (p.15). No que se refere ao fracasso, Cordié (1996) desenvolve a ideia de que este é reconhecido como a patologia do nosso tempo, julgamento de valor que opera com ideal e ao qual o sujeito a partir dessa referência se constitui.

Numa amarragem entre a omissão da história de um filho e o assumir essa criança num lugar de fracasso, Molina (2001) ressalta:

\footnotetext{
"Sabemos que tudo o que não é colocado em palavras exerce um efeito inibidor, obstáculo para a ampliação da função simbólica. Não é diferente com o silêncio em relação à origem de um filho ou a indisponibilidade parental em oferecer-lhe as condições para formular os seus questionamentos em relação à sua história: esse silenciamento pode ocasionar, na posição pessoal da criança, um certo sentimento de errância." (p.177)
}

A partir dessas colocações, surgem questionamentos frente ao lugar que Denis é convocado a ocupar na sua família, uma vez que, em nível inconsciente, algo aí se produz diante destes pais em relação ao lugar de filiação. Desta maneira, questiona-se: de que lugar, então, se trata? De um lugar de fracasso? Mas de que fracasso se fala? E o que faz com que este filho adotivo venha a preencher este lugar no âmbito familiar? Para essas questões, parecia que havia mais a ser dito 
e, assim, iniciou-se uma investigação com os pais acerca de suas motivações e desejos, conscientes e inconscientes, em relação à adoção.

O casal, num primeiro momento, mostrou-se resistente às investigações, dizendo que seus planos sempre foram ter dois filhos e adotar um terceiro. Cinco anos após o nascimento da primeira filha, o casal engravidou novamente, o que era há muito tempo desejado. Logo após engravidarem pela segunda vez, colocaram seus nomes na lista para a adoção, prevendo um longo período de espera. Contudo, antes mesmo de completar os três meses de gestação, o casal perde esse bebê. Ao mesmo tempo que se investigava, junto aos pais, o desejo desta adoção e a repercussão desta perda, Denis, em seu tratamento, apontava para algo que continuava em segredo. Durante a sessão seguinte, o menino falava cochichando (como a mãe também fazia quando queria contar algo que imaginava que o filho não soubesse), vendava meus olhos e me mostrava que escondia brinquedos como parte da brincadeira. Pensa-se, assim, numa dialética do revelar-esconder, falar-cochichar.

\section{O DESENROLAR DO CASO: A CHAVE PARA O CADEADO}

Nesta busca pela verdade, chamo primeiro a mãe a participar de uma sessão com Denis. Solicito que ele escolha um jogo para jogarmos os três enquanto conversávamos. Denis escolhe, então, um quebra-cabeça e, quando está prestes a terminar de montá-lo, percebo que havia escolhido o quebra-cabeça do patinho feio. Peço que fale sobre a imagem montada. Esta solicitação é feita considerando o entendimento psicanalítico acerca do brincar:

"Durante a hora da análise, o quadro que a criança nos apresenta não tem aparentemente sentido. Porém, o conteúdo de suas brincadeiras, o modo como brinca, os meios que utiliza, as mudanças em suas brincadeiras (...) todos são fatos que têm um sentido e que devemos interpretar como se interpretam os sonhos (...) observa-se que a criança fala enquanto joga ou desenha, comentando aspectos de sua atividade lúdica como faz o adulto com os elementos de seu sonho. Suas palavras têm valor de associações.” (ABERASTURY, 1996, p.19)

Respondendo à solicitação de que falasse a respeito da imagem montada, ele diz: “é o pato cagado”, o que a mãe entende como "pato adotado”. Então, pergunto: "pato cagado? Quem é o pato cagado?" Denis aponta para o patinho feio do quebra-cabeça e responde: "sou eu”. Nisto, a mãe intervém e lembra de uma vez em que seu marido teria feito uma brincadeira ao se referir ao momento em que estavam num processo de conhecer as crianças para adoção e que Denis estava todo sujo, “cagado” (sic), revelando os maus cuidados que recebia. Tal palavra havia marcado o menino, sendo tomada como um significante em sua história. 
Quanto à cadeia significante enquanto produto da cultura e da relação parental, Bastos (1999) refere:

“Um filho seria simplesmente o descendente de um pai e uma mãe, não fossem todas as significações que podemos encontrar aí. Muito além do produto biológico de uma cópula, o filho é feito de carne, mas também de significantes. Pode ser o filho que eu fui, ou aquele que eu queria ter sido." (p.79)

No que se refere ao jogo enquanto material analítico, é importante considerar o quebra-cabeça, jogo favorito de Denis, o qual aparece como um desejo e necessidade do menino em dispor das peças para montar sua história. Frente às colocações feitas e a escolha pelo tema do patinho feio, é importante considerarmos os achados de Mannoni (1987) quanto ao brinquedo:

“Assim, a criancinha, que, no seu brinquedo, reordena o seu mundo presente ou passado de acordo com a sua aspiração. Sua palavra surge então para tocar um adulto imaginário ou real (isto é, um companheiro imaginário). O discurso, que se processa na psicanálise, assim na criança como no adulto, nos remete, pois, não tanto a uma realidade quanto a um mundo de desejos e sonhos.” (p.10)

A sessão continua, e quando questiono sobre a perda do filho que havia sido concebido antes da vinda de Denis, sua mãe relata, com muita dificuldade e carregada de culpa que, aos três meses de gestação, ela estava dormindo quando acordou com fortes dores, foi ao banheiro e, quando percebeu, o feto havia caído e se perdido no vaso sanitário. A respeito desta colocação, nos resta observar que há algo similar entre um feto que cai no vaso e um menino "cagado". Ao que parece, no ponto em que termina a história de um, começa a de outro. Ainda na mesma sessão, o menino faz um lapso, dizendo "fala mãe, fala mãe, é tua vez de não contar” (sic), quando ele queria ter dito "é tua vez de contar”. Frente a estas colocações, Mannoni (1987) ressalta “...palavras ouvidas, mas esquecidas, que deixam seu vestígio ao nível do sintoma. Em uma análise, chega-se a discernir a marca das palavras (ditas ou não-ditas) sobre o somático” (p.11).

Diante desta revelação, pergunta-se: estaria aí a direção de resposta para a questão referida no início deste artigo, quando se indagava qual lugar a criança adotada é convocada a ocupar no imaginário parental? Todo pai e mãe, durante o período de gestação, constroem uma imagem, um ideal de filho esperado. Contudo, ao nascer, inicia-se imediatamente a montagem psíquica deste pequeno sujeito (HOYER, 2006), uma vez que, diante do nascimento do filho, os pais sofrem o luto pela perda do bebê imaginário, idealizado, pois não há como este pequeno sujeito, o bebê real, corresponder a tais expectativas. Da mesma forma, o filho adotado, assim como o biológico, é investido de fantasias inconscientes de sua mãe e pai. Ao mesmo tempo que é convocado a dar conta do desejo que 
não foi possível ser realizado por eles, os pais, isto é, ter um filho biológico. Neste sentido, Outeiral (2005) acrescenta: “Um filho antes de nascer povoa a imaginação de seus pais, ou seja, a projeção que eles fazem dele, é um filho imaginário. Todos nós, por mais que tenhamos filhos reais, teremos sempre outro(s) no imaginário." (p.52). No que se refere ao imaginário, Chemama (1995) conceitua:

“categoria do conjunto terminológico elaborado por Lacan, real, simbólico e imaginário (...). O imaginário deve ser entendido a partir da imagem. Esse é o registro do engodo, da identificação. Na relação subjetiva, é sempre introduzida alguma coisa fictícia, que é a projeção imaginária de um sobre a tela simples em que o outro se transforma. É esse o registro do eu, com aquilo que comporta de desconhecimento, de alienação, de amor e de agressividade, na relação dual." (p.104)

Pensando no entendimento acerca do imaginário de um filho, é importante assinalar o conceito de pai imaginário, visto que, para a psicanálise, há uma projeção dos pais para o filho enquanto ideal, e um retorno desta projeção, que interroga a eles o lugar que ocupam enquanto pais, isto é, “falar em filho imaginário obrigatoriamente é falar também de uma mãe e um pai imaginários” (OUTEIRAL, 2005, p.52). Para tanto, Outeiral (2005) compreende o pai imaginário enquanto projeção originária da interrogação: “Qual pai serei eu?”. Para o autor, a figura paterna constitui um ideal de pai, baseado na idealização internalizada e imaginada acerca da figura e lugar paterno, isto é, o pai imaginário está construído a partir das representações e significações do que venha a ser um pai. Não é necessário ser pai no real para ter a imagem e projeção de que pai será, pois o pai imaginário já existe nele.

Feitas as devidas colocações, pergunta-se que desejo e imaginário parentais estariam projetados para Denis? Deve-se considerar que a adoção de Denis é posterior à perda do bebê biológico - bebê este que saiu de cena, foi "cagado", caiu no vaso, "fracassou”. Isto origina uma perda não apenas simbólica, de uma imagem e imaginário que vinham sendo construídos, mas há também a perda no real, o que intensifica e dificulta a elaboração do luto parental. E se, como mencionado, o filho adotado é, da mesma forma, a promessa de realização parental, estaria aí, através dos significantes, “cagado” e "fracasso”, o lugar de Denis no imaginário de seus pais? Isto é, se o que comporta sua adoção é o retorno do filho perdido, podemos supor que o ideal e imaginário de filho para o casal, principalmente para a mãe, seria o de um filho que mantivesse viva a história deste fantasma? Estaria aí o gozo parental frente a estas duas histórias que se encontram, se comunicam e dão lugar a Denis enquanto significante do patinho feio? 
Desta forma, pode-se dizer que o imaginário, assim como o inconsciente, é estruturado enquanto linguagem. Sendo assim, fala, comunica e pergunta: o que minha mãe deseja? O que é que ocasionou minha vinda para esta família? Toda esta construção é importante e constitutiva para a criança e para a organização de lugares no direcionamento desta família. Contudo, mais tarde, tal imaginário deve ser abandonado, a fim de que a criança possa falar por si, sair do lugar de objeto e se constituir enquanto sujeito psíquico (HOYER, 2006; JULIEN, 2000).

Em sessão posterior, trabalhou-se o desenho do livro do cadeado com os pais de Denis. Os pais ficaram bastante curiosos com os detalhes do desenho, e ao pai logo chamou a atenção, apesar de Denis fazer de tudo para esconder, o esboço da criança que fora rabiscada por cima. Quando Denis é questionado a respeito de quem seria esta figura, prontamente responde: “é o morto” e segue dizendo: "é o fantasma!! Eu sou um fantasma, Buuuhhh, buhhhh” (sic). Dando continuidade, ele diz: "vou entrar dentro do livro" (sic), tirando algo de seu bolso que representava uma chave, e se escondendo por debaixo da mesa, como se tivesse, de fato, entrado no livro. Quando questionado aos pais sobre o que Denis estaria falando, surge a resposta: “Está claro, ele está falando do filho que perdemos" (sic).

Conforme Mannoni (1987), a partir do momento que a criança verbaliza o que de fato ocasiona sua doença, isto é, aquilo que o sintoma vinha encobrir, obtémse o que a autora denomina de "a chave da desordem somática”, o que significa caminhar em direção à cura. Assim, entende-se que, de maneira inconsciente, esta criança vem a ocupar o lugar deste filho perdido, quando houve um luto não elaborado. Seria, então, deste lugar que Denis traz sua fala como a de um bebê? E se esse bebê teve como destino a morte, essa seria a origem de seu fracasso? É como se este feto morto estivesse vivendo através de Denis, principalmente enquanto desejo materno, o que pode ser ilustrado pelo relato de um sonho que mobilizou muito esta mãe: "Sonhei que o filho (perdido) teria voltado e estaria com a idade dele (do Denis)" (sic). O desejo e a tentativa de amenizar a dor de um luto não elaborado fazem com que este fantasma esteja encarnado no filho adotivo. Conforme Freud (1915-1917/1974), em uma situação de luto “as pessoas nunca abandonam de bom grado uma posição libidinal, nem mesmo na realidade, quando um substitutivo já lhes acena” (p.276-277).

Diante deste relato clínico, consideram-se os achados de Mannoni (1987):

"O campo em que o analista opera: este campo é o da linguagem (mesmo se a criança ainda não fala). O discurso que se processa engloba os pais, a criança e o analista: é um discurso coletivo que se constitui em torno do sintoma apresentado pela criança. A perturbação de que se fala é objetivável (na pessoa da criança), mas a 
queixa dos pais, se tem por objeto a criança real, implica também a representação que o adulto se faz da infância. A sociedade confere à criança um estatuto, porque encarrega, por sua vez, de realizar o futuro do adulto: a criança tem por missão reparar o malogro dos pais, realizar-lhes os sonhos perdidos. As queixas dos pais a respeito de sua descendência nos conduzem assim, antes de tudo, à problemática própria do adulto." (p.9)

Em casos como esse, em que a adoção é realizada após a perda de um filho, questiona-se: a serviço de que esta adoção é feita? O mesmo questionamento é feito por Bernardino (1999), que ainda acrescenta: "Se o que causa o desejo de adotar é a morte do filho desejado, o bebê que vem aí no lugar do morto é chamado a tapar esta perda não elaborada, para fazer calar a dor do luto, ao mesmo tempo que para dizer dela” (p.79). Assim, à medida que a criança é convocada a ocupar lugar no desejo materno, resta a ela falar desse lugar, isto é, denunciá-lo. Segundo Freud (1915-1917/ 1974), “o luto, de um modo geral, é a reação à perda de um ente querido, a perda de alguma abstração que ocupou o lugar de um ente querido, como o país, a liberdade, ou o ideal de alguém, e assim por diante" (p.275).

Importante salientar que há, na verdade, dois lutos em jogo. Existe o luto da mãe adotiva, que perde o segundo filho por um aborto, assim como, para o menino adotado, houve a perda de sua mãe biológica quando foi abandonado. Conforme Levinzon (2004), a adoção tem origem nesta separação entre a criança e a mãe biológica. Especialmente quando a criança ainda é bebê, é comum repercutir em um trauma, pois, para esse bebê, há a perda do objeto que lhe ofereceu agradáveis condições e proteção durante o período de gestação.

Quanto à problemática do fracasso trazida neste caso, faz-se necessário relembrar que houve, por muitos anos, para esse casal, a impossibilidade de ter filhos, algo que muito desejavam. Mais precisamente, foram dez anos de espera: cinco anos entre o nascimento da primeira filha e o bebê que não nasceu, e mais cinco até a adoção de Denis. No próprio discurso do casal, ambos consideravam a dificuldade de ter filhos como uma questão psicológica. O que pode ser confirmado pelo fato de a mãe adotiva de Denis ter engravidado cerca de oito meses após sua adoção. Segundo os autores, esse é um fato bastante comum em casais que enfrentam dificuldades para engravidar devido a estresse psicológico (LEVINZON, 2004; BERNARDINO, 1999). Nesse caso, seria então o fracasso de Denis uma projeção deste fracasso parental? No que se refere a esse movimento familiar relatado, abre-se a questão: o que quer, então, uma família? Para este questionamento, Outeiral (2005) apresenta uma resposta: 
“É possível pensar que cada família tem uma identidade própria e, como tal, fantasias, situações traumáticas, perdas, mitos familiares, segredos e uma história. Trata-se, na verdade, de um agrupamento humano, em constante evolução, constituindo com um intuito básico de prover a subsistência de seus integrantes e protegê-los.” (p.11)

\section{CONSIDERAÇÕES FINAIS}

Diante do caso apresentado, verifica-se que, da mesma forma como descrito pelos autores, os problemas de aprendizagem muitas vezes mostram-se como sintoma para tamponar outras questões que não a dificuldade escolar em si. Muitas vezes, referem-se a dificuldades em relação a saberes ocultos, silenciados, como visto no caso de Denis (CORDIÉ, 1996; FERNANDEZ, 1991). Da mesma forma, os pais de Denis, num primeiro momento, buscaram tratamento para seu filho a partir da queixa de dificuldade escolar. Contudo, essa desempenhou papel secundário, na medida que se trabalhou como foco terapêutico o segredo da adoção enquanto acesso ao conhecimento, ou seja, a melhora do rendimento escolar é entendida, neste caso, como consequência do acesso ao saber — sendo esse trabalho realizado nas sessões, frente à verdade de sua história. Seu pai, inclusive, refere, em sessões mais próximas à finalização, não atribuir a questão da dificuldade escolar como demanda de tratamento de seu filho.

Considerando a proposta de terapia breve, Denis apresentou evoluções significativas. Tais evoluções podem ser evidenciadas tanto por meio das observações clínicas, como pelos apontamentos de sua escola. Conforme sua professora: "quanto à aprendizagem, ele tem se desenvolvido bem, está mais atento, o que tem contribuído na hipótese da escrita”; ressalta, ainda, que seu desenvolvimento cognitivo está preservado. No que se refere à atenção de Denis, cabe lembrar a fala materna trazida em sessões iniciais: "ele tem boa capacidade de memória, mas é desatento" (sic). Contudo, agora se anuncia uma melhora nesse aspecto, sendo possível a esse menino não mais negar sua memória, mesmo que ela lhe ofereça lembranças ruins (abandono da mãe biológica), pois isso não se refere ao seu momento atual, mas sim à sua história passada. Em relação a isto, a professora acrescenta: "a família melhorou bastante, parece haver maior satisfação, parece que estão entendendo melhor o Denis”. Assinala, assim, a conquista de seu lugar junto à família e o recebimento do tão solicitado olhar parental, o que parece não ter ocorrido na experiência com a mãe biológica.

Quanto às questões acerca da filiação, entende-se que Denis ocupe esse lugar de filho, na estrutura familiar. Falhas em relação à filiação foram apontadas durante esta exposição; contudo, ao longo das sessões, percebe-se que a filiação se modificou, o que aparece na fala de Denis, trazida por sua mãe, quando ela 
o ajuda a arrancar seu dente de leite e ele lhe responde: "para mãe, para mãe, como tu podes fazer isso com teu próprio filho?" (sic). Frente a essa frase, é possível evidenciar o laço de filiação e o quanto sua mãe ainda opera na função paterna (tirar o dente). Contudo, Denis protesta, convocando-a a ocupar o lugar materno, de que ela reconheça o pai como aquele que deve arrancar o seu dente - isto é, que o pai opere a castração.

Reivindicações como essa são também observadas em relação ao lugar e aos significantes de "patinho feio" e de "pato cagado" demandados em sua história, os quais foram apresentados ao longo deste artigo, sobretudo por meio do relato do ato lúdico desse paciente. Tais reivindicações ilustram o quanto esse menino vem cada vez mais ocupando o lugar de sujeito, principalmente no contexto familiar.

Tanto a adoção de uma criança como a chegada de um filho biológico ocupam um lugar privilegiado no desejo inconsciente parental. Tal desejo, no caso de Denis, pareceu tamponar duas faltas narcísicas desses pais: encobrir o fracasso parental frente à dificuldade que enfrentaram, por dez anos, de gerar outros filhos biológicos, bem como amenizar a dor do filho morto. Logo, tanto o fracasso como o luto não elaborado contribuíram, nessa história, para o lugar de Denis enquanto patinho feio no imaginário parental.

\section{REFERÊNCIAS}

ABERASTURY, A. (1996) Abordagens à psicanálise de crianças. Porto Alegre: Artes Médicas.

BASTOS, R. F. (1999) “A criança no discurso Parental”, in I Congresso Internacional de Psicanálise e suas Conexões. Trata-se uma criança. Rio de Janeiro: Companhia de Freud.

BERNARDINO, L. M. F. (1999) “Mãe é uma só”. Associação Psicanalítica de Porto Alegre, in CALLIGARIS, C. Associação Psicanalítica de Porto Alegre. Educa-se uma criança. 2. ed. Porto Alegre: Artes e Ofícios, p.75-83.

(2007) "A intervenção psicanalítica nas psicoses não decididas da infância”, in JERUSALINSKY, A.; COSTA, A.; PALOMBINI, A. L.; TREVISAN, E. ASSOCIAÇÃO PSICANALÍTICA DE PORTO ALEGRE. Psicose: aberturas da clínica. Porto Alegre: Appoa.

CHEMAMA, R. (1995) (Org.) Dicionário de psicanálise. Porto Alegre: Artes Médicas. 
CORDIÉ, A. (1996) "O fracasso escolar, patologia do nosso tempo", in Os atrasados não existem: psicanálise de crianças com fracasso escolar. Porto Alegre: Artes Médicas.

CORDIOLI, A. V. (1998) Psicoterapias: abordagens atuais. 2. ed. Porto Alegre: Artmed.

DOLTO, F. (1996/2004) Quando surge a criança. 3v. Campinas: Papirus.

ENÉAS, M. L. E.; FALEIROS, J. C.; SÁ, A. C. A. (2000) Uso de psicoterapias breves em clínica-escola: caracterização dos processos com adultos. Universidade Presbiteriana Mackenzie. Psicologia: Teoria e Prática. 2(2): p.9-30.

FERNANDEZ, A. (1991) “O fracasso na aprendizagem”, in A inteligência aprisionada: abordagem psicopedagógica clínica da criança e sua família. Porto Alegre: Artes Médicas.

FREUD, S. (1915-1917/1974) "Luto e melancolia", in Edição standard das obras psicológicas completas de Sigmund Freud, v. XIV, p. 271-291. Rio de Janeiro: Imago.

HOYER, C. (2006) Os riscos na constituição psíquica, in I Congresso Internacional de Psicopatologia Fundamental e VIII Congresso Brasileiro de Psicopatologia Fundamental. Belém. Disponível em: http://www.fundamentalpsychopathology.org/anais2006/4.59.3.2.htm. Acesso em: 3/5/2008.

JULIEN, P. (2000) Abandonarás teu pai e tua mãe. Tradução Procópio Abreu. Rio de Janeiro: Companhia de Freud.

LACAN, J.; MILLER, J. (1964/1998) O seminário, livro 11: Os quatro conceitos fundamentais da psicanálise. 2 ed. Rio de Janeiro: Jorge Zahar. (Campo Freudiano no Brasil)

LEVINZON, G. K. (2004) Adoção. São Paulo: Casa do Psicólogo. (línica Psicanalítica)

MANNONI, M. (1987) A criança, sua "doença” e os outros: o sintoma e a palavra. 3 ed. Rio de Janeiro: Guanabara Koogan.

MENEGOTTO, L. M. O. (2006) "Da filiação à inclusão: uma articulação entre psicanálise e educação”, in MOURA, E. P.G. (Org.) Educação, cultura e trabalho. Novo Hamburgo: Feevale.

MOLINA, S. E. (2001) "A intervenção psicanalítica em crianças adotivas”, in Os nomes da tristeza. Revista da Associação Psicanalítica de Porto Alegre/Associação Psicanalítica de Porto Alegre, n. 21.

OUTEIRAL, J. O. (2005) “Trabalho com grupos na escola”, in OUTEIRAL, J. O. O mal-estar na escola. 2. ed. Rio de Janeiro: Revinter.

PAÍN, S. (1991) "O pensamento da Ignorância”, in —_. A função da ignorância. Porto Alegre: Artes Médicas.

SANCHES, R. M. (2002) A função da verdade, in Psicanálise e educação: questões do cotidiano. São Paulo: Escuta.

SPITZ, R. A. (1979/1996) O primeiro ano de vida: um estudo psicanalítico do desenvolvimento normal e anômalo das relações objetais. 7. ed. São Paulo: Martins Fontes (Coleção Psicologia e Pedagogia)

Laura Kolberg Lipp

lauralipp@gmail.com 